\title{
Changes in singing performance and fMRI activation following right temporal lobe surgery
}

Sarah J. Wilson, ${ }^{a, b, c}$ David F. Abbott, ${ }^{b, c}$ Chris Tailby, ${ }^{a, c}$ Ellen C. Gentle, ${ }^{a, c}$ Dawn L. Merrett, ${ }^{a, c}$ and Graeme D. Jackson ${ }^{b, c}$

a Melbourne School of Psychological Sciences, The University of Melbourne, Australia

b Melbourne Medical School, The University of Melbourne, Australia

c Florey Institute of Neuroscience and Mental Health, Melbourne Brain Centre, Austin Hospital, Australia

Running title: Cortical reorganisation of singing

Corresponding Author:

Associate Professor Sarah Wilson, Melbourne School of Psychological Sciences, The University of Melbourne, Victoria, 3010, Australia

Ph: +613 8344-739I; Fax: +613 9347-6618; E-mail: sarahw@unimelb.edu.au 


\section{ABSTRACT}

Introduction: This study arose in the context of having to estimate risk to the musical abilities of a trained singer (patient AM) recommended for right anterior temporal lobectomy (RATL) to ameliorate medically intractable seizures. To date there has been no systematic investigation of reorganisation of musical functions in the presence of epileptogenic lesions, although it is well established that RATL can impair pitch processing in nonmusicians.

Methods: Using fMRI, we compared the network activated by covert singing with lyrics in AM before and after surgery, while taking language activation and singing expertise into consideration. Before surgery, AM showed lower pitch accuracy of singing relative to individuals of similar experience (experts), thus we compared her to 12 healthy controls matched for singing pitch accuracy.

Results: We found atypical organisation of AM's singing network before surgery in the presence of a malformation of cortical development, including partial activation of the singing network of pitch-matched controls, and diffuse activation along the midline spreading laterally into association cortex, typical of generalised cortical hyperexcitability in intractable epilepsy. After tailored RATL, AM showed striking behavioural and neuroimaging changes, including significant improvement in pitch accuracy of singing relative to controls $(p=.026)$ and the subjective experience of being a more technically proficient singer. This was accompanied by a significant reduction in cortical activation ( $p<.05$, corrected), with a more focal, expert-like pattern of singing activation emerging, including decreased involvement of frontal language regions. These changes were largely specific to singing, with AM showing language activation and performance similar to controls.

Conclusions: This case provides evidence for selective disruption of the singing network that reorganised after successful resection of an epileptogenic lesion and likely occurred through decoupling of the singing and language networks.

(287 words)

Keywords: fMRI; Singing; Language; Epilepsy surgery; Outcome 


\section{Introduction}

The right temporal lobe has a well-established role in musical abilities, with the posterior superior temporal gyrus mediating fine-grained pitch perception (Hyde et al., 2008; Zatorre et al., 2002), while more anterior regions underpin pitch working memory (Zatorre and Samson, 1991; Zatorre et al., 1994) and the representation of tunes (Hsieh et al., 20I I; Platel et al., 2003; Samson \& Zatorre, 1991). These abilities are important not only for music listening but also performance, and constitute core cognitive components of singing. It is not surprising then, that in professional singers concerns may arise about the potential consequences of undergoing right temporal lobe resection for the treatment of medically intractable epilepsy.

It has been increasingly recognised that epilepsy is a disease of brain networks (Carney et al., 2010; Pillay et al., in press), and that seizures can propagate along neurocognitive pathways selectively disrupting particular functions (Waites et al., 2006). In other words, cognitive dysfunction can provide a marker of the underlying seizure network (Wilke et al., 20I I), including the extent to which the network may have reorganised. Estimating the cognitive risk of cortical resection is complex as multiple factors can interact to determine the outcome for a given individual (Baxendale, 2008; Saling, 2009). For example, developmental lesions can give rise to the onset of habitual seizures at varying ages that can be associated with different patterns of reorganisation, including intra- and inter-hemispheric shifts in higher cognitive functions such as language (Adcock et al., 2003; Federico, 20II; Gaillard et al., 2007; Mbwana et al., 2009; Sveller et al., 2006). Pre-surgical decision-making must strive to identify functional reorganisation on a patient-by-patient basis, with the aim of sparing functional tissue to preserve pre-surgical capacity. Cognitive risks should be minimised but weighed-up against the chance of complete seizure freedom, with recent research highlighting the double impact of suboptimal seizure relief and cognitive deficit on post-operative quality of life (Langfitt et al., 2007 Wilson et al., 2007).

To date, there has been no systematic investigation of the reorganisation of musical functions in the context of epileptogenic lesions. It has been well documented, however, that right anterior temporal lobectomy (RATL) can selectively impair pitch and melody discrimination and pitch 
working memory in nonmusicians (Dennis and Hopyan, 200I; Liégeois-Chauvel et al., 1998; Samson 1999; Samson and Zatorre, 1988, 1991, 1992; Wilson et al., 1999; Wilson and Saling 2008; Zatorre, 1985). In musicians the research is more limited, and includes one case report of preserved pitch naming ability (absolute pitch) following left temporal lobectomy (Zatorre, 1989), and one case of expressive amusia (including impaired singing) following a right frontal lobe resection in an amateur musician (McChesney-Atkins et al., 2003).

Thus, accurate estimation of risk to musical abilities is currently hampered by a lack of available evidence, despite findings that patients can harbor a range of expectations of postoperative life including improved cognitive and vocational functioning associated with seizure relief (Chin et al., 2006; Rose et al., 1995; Taylor et al., 200I; Wheelock, 1998; Wilson et al., 1998). This situation is compounded by the different cortical organisation of musical functions in musicians and nonmusicians, which is thought to reflect years of training and early exposure to a musical environment in instrumental musicians (Merrett and Wilson, 20 I2; Münte et al., 2002). Despite its ubiquitous nature, less is known about singing with only a few functional imaging studies directly comparing cortical organisation in expert and nonexpert singers (Formby et al., 1989; Kleber et al., 2010; Wilson et al., 20I I; Zarate and Zatorre, 2008). These studies generally support a more focal (or task relevant) pattern of activation in experts, including more refined networks for audio-vocal integration (Zarate and Zatorre, 2008), more focal activation in ventral sensorimotor and subcortical motor areas important for kinaesthetic motor control (Kleber et al., 2010), and more specialised circuits in the left hemisphere when singing with lyrics (Wilson et al., 20II), all of which are presumed to underpin more accurate vocal performance.

The extent to which music and language are mediated by independent neural networks and constitute distinct cortical functions is currently debated. Singing with lyrics (referred to as vocal singing) provides an ideal paradigm for investigating this issue as it shares features common to both (Schön et al., 2005). Neuroimaging research of vocal singing in nonmusicians has indicated considerable cortical overlap, suggesting that singing and language functions are proximally located (Brown et al., 2004, 2006; Callan et al., 2006; Özdemir et al., 2006; Wilson et al., 20I I). This is 
supported by research showing that syntactic processing in language and music rely on activity in the left inferior frontal gyrus (Sammler et al., 20I I), and that music training can benefit a range of language skills, such as phonological awareness, tonal language learning, and reading abilities (Degé and Schwarzer, 20 II; Moreno et al., 2009; Marie et al., 20I I). Recently however, Wilson et al. (20II) demonstrated that during covert vocal singing expert performers show less cortical overlap with language structures compared to nonexperts, likely accounting for their more tuneful performance.

The present study arose in the context of having to estimate risk to the musical abilities of a trained singer (patient AM) recommended for RATL to treat medically intractable temporal lobe epilepsy (TLE). Since TLE is associated with greater atypical language organisation and disruption of functional language networks (Waites et al., 2006), an expertise-dependent degree of overlap between the singing and language networks raises the possibility that TLE may affect the organisation of music functions, and this might vary with music expertise. Thus, our aim was to estimate risk to AM's singing function posed by right anterior temporal resection taking language activation and singing expertise into consideration, so as to minimise any potential deficits through a more tailored surgical resection. To do this accurately we needed to identify AM's singing network and assess any evidence for reorganisation in the presence of a developmental epileptogenic lesion using behavioural measures and activation patterns obtained from fMRI. We hypothesised that any changes in AM's singing behaviour would be accompanied by altered patterns of functional activation, potentially signifying reorganisation of function associated with the disruptive effects of the epileptogenic lesion. Before surgery we compared AM with a group of healthy controls matched for pitch accuracy of singing using behavioural and in-scanner singing and language tasks. After surgery, we again compared AM to the healthy controls as well as contrasting her pre- and post-operative scans to assess any changes following a tailored right temporal lobe resection. 


\section{Methods}

\section{I Participants}

\section{I.I Patient AM}

At the time of pre-surgical assessment, AM was a 26 year old left-handed female. She grew up in a musical family, commencing formal training on the piano at age 10, and voice (singing) training at age 12 . She played the piano for 10 years but considered voice her principal instrument, with 14 years combined vocal training and regular public performances. She also learnt to play the clarinet at secondary school for six years, had completed formal training in music theory (including reading and writing music), and had undertaken tertiary music education to a Masters degree level as part of training for a professional career in music. She was actively involved in several choirs and musicals, including regular solo work as part of weekly choral performances, although increasing frequency of seizures was impacting her ability to perform, with some seizures occurring during solo performances. AM practiced for a minimum of two hours daily. She reported no history of absolute pitch ability, nor family history of absolute pitch.

AM had a severe febrile illness in childhood that she thought may have been called meningitis, but documentation of this illness was unavailable. She also had mild hearing loss in her left ear that had remained stable since childhood. Her habitual focal seizures commenced at age 18 years. On pre-surgical assessment she was averaging 2-3 seizures per week and was being treated with carbamazepine (1000 mg/day), levetiracetam (1000 mg/day), topiramate (400 $\mathrm{mg} /$ day), and clobazam (10 mg p.r.n). Inpatient video-EEG monitoring showed seizures originating from the right temporal lobe. This was supported by a right temporal focus on ictal-SPECT, and right temporal hypometabolism on FDG-PET. Structural MRI using a 3T TI FSPGR-sequence showed cortical dysplasia in both temporal lobes, mainly in the superior temporal gyrus bilaterally, as well as a smaller right temporal lobe with the abnormality extending into the temporal pole and medially involving the right parahippocampal gyrus (see Fig. IA). T2-relaxometry times indicated mild signal increase in the right anterior temporal lobe white matter (right $=1 \mid 2$ ) and both hippocampi (left $=107$, right $=107)$, the latter likely reflecting minor damage from 
secondary effects of seizures (Scott et al., 200I). Neuropsychological assessment revealed normal intellectual function (Verbal IQ I0I, Performance IQ 87) but evidence of psychomotor slowing (borderline range). Memory for complex auditory-verbal information was reduced (35th percentile) in contrast to intact encoding and recall of visuo-spatial material ( $>80^{\text {th }}$ percentile). [Insert Figure I about here]

AM underwent a tailored RATL that preserved the superior temporal gyrus but involved en-bloc resection of the lateral temporal neocortex extending back $6 \mathrm{~cm}$ on the middle temporal gyrus, and $7 \mathrm{~cm}$ on the inferior temporal gyrus. The resection included a $6 \mathrm{~cm}$ en-bloc resection of the mesial structures including the hippocampus, parahippocampal gyrus, and the amygdala (see Fig. IB). Post-operative histopathology confirmed a focal malformation of cortical development in the neocortical specimen, and changes consistent with mild hippocampal sclerosis. After surgery, AM was seizure free with the exception of one suspected nocturnal generalised tonic clonic seizure in the context of anticonvulsant withdrawal. Neuropsychological assessment nine months post-surgery showed a decline in visuo-spatial memory and psychomotor speed but improved auditory-verbal memory, consistent with a typical pattern of cerebral organisation. Post-surgical music assessment was conducted approximately 15 months after surgery by which time AM was on monotherapy for seizures (carbamazepine $1000 \mathrm{mg} /$ day). She was also taking sertraline (50 $\mathrm{mg} /$ day) for increased anxiety including some episodes of panic after surgery.

\section{I.2 Healthy control sample}

Twelve healthy controls (6 females) with similar pitch accuracy of singing to AM (see Results) were recruited from The University of Melbourne, University-related choirs, and communitybased volunteers. All controls were drawn from a larger pool of 26 individuals of varying singing expertise who participated in a previous study investigating the cortical organisation of singing (Wilson et al., 20ll). They underwent a medical screen for significant neurological, psychiatric, and hearing impairments including audiogram. They also completed a detailed history of their music training and background using the Survey of Musical Experience (Wilson et al., 20I I) with 
additional questions focusing on singing training and experience. No participant reported absolute pitch ability.

\subsection{General experimental procedures}

The study received approval from the relevant Human Research Ethics Committees and all participants gave written informed consent in accordance with the Declaration of Helsinki. Broadly, the experimental procedures included behavioural measures of overt vocal singing and language out-of-scanner, and functional imaging measures of covert vocal singing and language inscanner, using methods previously published by our group (Wood et al., 200I; Wilson et al., 20II). Covert language and singing paradigms were used to minimise movement and respiratory artefacts and to focus the analysis on higher cognitive representations rather than the primary sensory and motor aspects of singing and speech production (Wilson et al., 20l I). This was pertinent given the role of the right anterior temporal lobe in core cognitive components of singing.

\subsection{Out-of-scanner assessment}

Behavioural assessment of pitch accuracy involved digitally recording the singing of each participant using ProTools LE (DIGI00I hardware, ProTools LE software, version 5.I). After listening to a recorded template, participants sang the melody of the main theme of the Finale of the William Tell Overture by Rossini on the syllable 'deh'. Pitch accuracy was quantified using Praat (version 4.3.22 for Mac OSX). We estimated each participant's starting pitch from the average of the fundamental frequencies of the first three notes (with the same pitch) and then calculated the deviation of subsequent pitches from the played template relative to this starting pitch. In total, 42 notes were each assigned a score out of five reflecting the percent variation of pitch ratios from the expected ratios $(5= \pm 2.5 \%, 4= \pm 2.5-5.0 \%, 3= \pm 5.0-7.5 \%, 2= \pm 7.5-10.0 \%, I= \pm 10.0-$ 12.5\%). This produced a score out of 210 that was then converted to a pitch accuracy score ranging from 0 (low) to 100\% (high; see Wilson et al., 20ll). 
To assess that each participant's basic pitch perception skills were intact, we also administered a pitch working memory task developed by Zatorre et al. $(1991,1994)$ that has been shown to be sensitive in temporal lobectomy patients. Participants were presented with a target tone followed by a comparison tone that was separated by an interval of $1650 \mathrm{msec}$. In half the trials, the target and comparison tones differed by I, 2, or 3 whole tones, while in the remaining trials the tones were identical in pitch. The interval between the tones was filled with silence in the control condition, thus constituting a test of pitch discrimination, and six distractor tones in the interference condition, thus constituting a test of pitch working memory. Behavioural assessment of language was based on standardised administration of the Controlled Oral Word Association Test (COWAT, Strauss et al., 2006), as this is the overt equivalent of our covert inscanner verbal fluency task (Wood et al., 200I).

\subsubsection{Cognitive activation paradigms}

The in-scanner tasks were performed before scanning to familiarise participants with the cognitive activation paradigms and to obtain behavioural measures of performance accuracy. After scanning, detailed questioning was undertaken to ensure that each participant adequately completed the tasks, including ratings of the familiarity of the lyrics and tune of the song used in-scanner (Wilson et al., 20II).

The cognitive paradigms were of block design. The covert vocal singing task involved repeatedly singing the first two lines of the chorus of a well known Australian folk song, Waltzing Matilda 'in mind', alternated with rest (sing-rest). A template of the song was played to participants prior to each $18 \mathrm{sec}$ task-block to promote a consistent rate of performance inscanner. The played song template had a duration of $10 \mathrm{sec}$, allowing almost two complete repetitions of the song in each task-block. During rest-blocks (18 sec), participants were asked to 'relax and try not to think about anything in particular'. The visual signals "sing" and "rest" were used to control the commencement and cessation of imagined singing and rest in each block. 
The covert language task (speech-rest) alternated rest-blocks (36 sec) with verbal fluency (36 sec) using orthographically-cued lexical retrieval (OLR). This task was employed as it allows substantive activation and thus localisation of the language network at an individual level (Abbott et al., 2010; Wood et al., 200I). During task-blocks, participants were visually presented with a letter of the alphabet and asked to covertly generate as many words as possible beginning with that letter (2 different letters per task-block, $18 \mathrm{sec}$ each). Rules included avoiding proper nouns and derivatives or extensions of a given word (e.g., run, running). The singing and language tasks constituted one functional run each. The functional run for singing contained eight task-blocks and nine rest-blocks in total, while the language run comprised four task-blocks and five rest-blocks in total. Functional runs were presented in a fixed order (speech-rest followed by sing-rest) to reduce random error and ensure consistency given our design compared a single patient to a group.

\subsubsection{Image acquisition}

Functional MRI was performed using a 3.0 tesla GE Signa LX whole body scanner (General Electric, Milwaukee, WI) with standard birdcage quadrature transmit-receive head coil. Participants were fixed using a Velcro strap over the forehead. Functional images were acquired using a multi-slice Echo Planar Imaging (EPI) sequence (single shot gradient recalled echo) providing T2*-weighted blood-oxygenation-level dependent (BOLD) contrast (Ogawa et al., 1990). Functional MRI acquisition parameters were as follows: repetition time $(T R)=3.0 \mathrm{sec}$, echo-time $(T E)=40 \mathrm{~ms}$, flip-angle $=60^{\circ}, 25$ axial oblique slices $4 \mathrm{~mm}$ thick $+\mathrm{Imm}$ gap, field of view $(F O V)=24 \mathrm{~cm}, 128 \times 128$ matrix, $1.88 \times 1.88 \mathrm{~mm}$ in-plane. Thus an image volume consisting of a series of slices covering the whole brain was acquired each TR. The first four image volumes acquired in each run were automatically discarded to allow magnetisation to reach a steady-state.

The collected images were pre-processed using Statistical Parametric Mapping software (SPM8 release 3408; Wellcome Department of Imaging Neuroscience, London, UK) with the aid of the iBrain ${ }^{\mathrm{TM}}$ analysis toolbox for SPM (Abbott et. al. 20I I) and iBrain ${ }^{\mathrm{TM}}$ (Abbott \& Jackson, 
200I). For the control participants, images were first slice-time corrected, realigned, then spatially normalised to the standard EPI template supplied with SPM8, which is approximately in the space of the 152 brain template of the Montreal Neurological Institute (see Wilson et al., 20I I for further details). Images were then smoothed with an isotropic Gaussian kernel of full-width-athalf-maximum $(\mathrm{FWHM})=8.0 \mathrm{~mm}$

In order to account for the effects of AM's surgical resection on the normalisation process, all of her pre- and post-surgical images were spatially normalised to a standard space (the SPM EPI template) via her pre-surgical speech-rest scans as these were free of confounds associated with resected tissue. Specifically, we determined realignment transforms of slice-timecorrected images in each run to the optimum within-run realignment target determined in iBrain $^{\mathrm{TM}}$. We then determined the non-linear spatial transform that spatially normalised the target in each run to the mean of the slice-time corrected, realigned pre-surgical speech-rest scans. For the post-surgical runs, this normalisation was accomplished after masking out of the pre- and post-surgical scans the region of the surgical resection as defined manually from a T2 weighted post-surgical anatomical image. We then determined the nonlinear warp that converted AM's pre-surgical speech-rest scan to standard space. Following this, all of her slice-time corrected, realigned scans (sing-rest before and after surgery, and speech-rest before and after surgery) were normalised to standard space by application of the appropriate combined transformations. In other words, all of AM's images were first co-registered to her pre-surgical EPI, which was then normalised to the EPI MNI template of SPM. The transforms thus derived were then combined and applied to the original images to yield images in MNI space.

\subsection{Data analysis}

We used one-sample t-tests to compare the out-of-scanner behavioural performance of AM to the pitch-matched controls first before surgery, and then after surgery. The pitch accuracy data, pitch discrimination, pitch working memory, and COWAT scores were analysed using IBM SPSS 
Statistics (version 19 for Mac OS X; www.spss.com), with $\mathrm{p}<.05$ (two-tailed) used to determine statistical significance.

Statistical analysis of the functional imaging data was conducted in SPM8 with the aid of the iBrain ${ }^{\mathrm{TM}}$ analysis toolbox for SPM using a general linear model. The first rest-block of each scanning run was disregarded from the imaging analysis to allow participants plenty of time to settle when each run commenced. In addition to the regressor modelling the task effect of interest, effects of no interest comprising the six rigid-body transformation parameters estimated during image realignment pre-processing were included in the model as estimates of residual variability in the fMRI signal due to participant motion. Prior to estimation, the fMRI data and design matrix were high-pass filtered (cut-off $=128 \mathrm{sec}$ ) to remove slow drifts in the signal due to scanner instability and slow physiological effects, and pre-whitened to correct for autocorrelation in the data, modelled as a first-order autoregressive process (Friston et al., 2002). The BOLD response of the task compared to rest state was modelled assuming the SPM canonical hemodynamic response function (HRF) and assessed using unpaired t-tests. Individual maps were first thresholded at $\mathrm{p}<.00 \mathrm{I}$ (uncorrected) and voxels considered significant if they belonged to a cluster size that survived a threshold of $\mathrm{p}<.05$ corrected for topological false discovery rate (FDRc) (Chumbley and Friston, 2009).

Resultant statistical parametric maps are displayed in colour and in radiological convention (left is participant's right), superimposed onto the mean of the unsmoothed spatially normalised EPI images. We also constructed penetrance maps to summarise individual differences in activation missed by group averaging (Berl et al., 2006). These display (in colour) activated voxels where two or more participants were significant, with each individual's map corrected at topological FDRc $(p<.05)$, providing a view of the spatial consistency of activation among participants (Fox et al., 1996). Voxel-based group analysis was undertaken using mixed (random) effects analysis to permit valid population inference. Resultant maps were first thresholded at $\mathrm{p}<$ .01 (uncorrected) and voxels considered significant if they survived a threshold of $p<.05$ FDRc. 
To examine patterns of functional activation associated with covert vocal singing in AM before and after surgery, we first used a multi-session analysis from the fMRI model specification module of SPM8 to compare her pre- and post-operative sing-rest scans. We also assessed evidence for reorganisation of singing or language function by comparing AM's pre-operative patterns of $\mathrm{fMRI}$ activation for sing-rest and speech-rest to the pitch-matched controls using a two-sample t-test. We then used this same approach post-operatively to assess any changes following a tailored RATL. Significant clusters in statistical parametric maps that appeared to reflect uncorrected pulsatile motion of the CSF (abutting activations and deactivatons straddling a CSF-brain boundary) were discarded, comprising I of 37 clusters across seven maps. Neuroanatomical labels of regions of significant activation were obtained using the HarvardOxford Cortical and Subcortical Structural Atlases within FSL View (3.0, Desikan et al., 2006). Because spatial normalisation has limited accuracy, the gyral location of activation peaks was also reviewed on the MR scans of individual participants by a neuroanatomical expert (author GDJ).

\section{Results}

\section{I Behavioural findings: AM's vocal singing and language performance}

\section{I.I Atypical singing performance before surgery}

Despite engaging in public performance for 14 years, AM showed significantly lower pitch accuracy of singing $(\sim 30 \%$ reduced $)$ relative to individuals of similar singing experience $(\mathrm{t}(9)=$ I I.067, $\mathrm{p}<.00 \mathrm{I} ;$ Table I). Thus, we compared her to 12 healthy controls selected on the basis of their pitch accuracy scores (mean $=52 \%)$, who fell < I SD $( \pm$ I5\%) from AM's score. On average, these individuals had $<$ I year of singing experience (Table I).

\section{[Insert Table I about here]}

As expected, AM's performance of the out-of-scanner singing task showed no significant difference from the healthy controls for mean pitch accuracy of singing. She performed at ceiling levels on the pitch discrimination and pitch working memory tasks, and showed no significant differences from the mean scores of pitch-matched controls (Table I, p > .05 for all comparisons). 
For language, AM's performance of the out-of-scanner verbal fluency task did not differ significantly from the mean performance of the pitch-matched controls $(p>.05)$ and was commensurate with normative data published for this task (Table I).

\subsubsection{Improved singing performance after surgery}

Following tailored RATL, AM's pitch accuracy score increased by 10\% (Table I), signifying reduced error in her ability to match each pitch of the familiar tune relative to her starting note. This meant that her overt singing performance had significantly improved compared to the healthy controls with whom she was pitch-matched before surgery $(\mathrm{t}(\mathrm{II})=-2.578, \mathrm{p}=.026)$. Although her pitch accuracy still fell below expert levels $(t(9)=7.519, \mathrm{p}<.001$; Table I), at follow-up I5 months after surgery AM spontaneously described herself as a technically more accurate and 'less emotionally based' singer. She also commented that members of her choir had noticed an improvement in her sight-singing, which she ascribed to no longer relying on a technique she routinely used before surgery, of imagining each note played on a piano before singing the correct pitch. AM's pitch discrimination and pitch working memory scores remained unchanged (and at ceiling levels), and her language performance for the out-of-scanner verbal fluency task did not statistically differ from controls ( $p>.05$ for all comparisons) and remained commensurate with normative data (Table I).

\subsection{Neuroimaging findings: Activation for vocal singing and language}

\subsection{More focal singing activation for AM after surgery}

To investigate the neurobiological correlates of AM's improved singing performance after surgery, we first compared her pre- and post-operative sing-rest scans. Before surgery, AM did not show the expected focal (or task relevant) pattern of $\mathrm{fMRI}$ activation of an expert singer despite her substantial experience. Rather, she showed a distributed pattern that was notable for its diffuse activation of midline structures and association cortex (Fig. 2A). This atypical pattern included partial activation of the network previously described for nonexpert singers (Wilson et al., 20I I) 
that was most pronounced in right middle frontal, left medial superior frontal and inferior frontal gyri, as well as bilateral cerebellum. However, it also included regions not typically activated during covert singing, such as the cuneus and precuneus (midline), and lateral posterior association cortices, while bilateral activation usually seen in the superior temporal gyri was not evident (see Fig. 2D and Fig. 2F; see also Wilson et al., 20I I).

\section{[Insert Figure 2 about here]}

Consistent with her improved singing performance after surgery, AM showed a strikingly more focal pattern of post-operative activation during sing-rest that involved structures typically activated during covert vocal singing, such as the right middle frontal and left medial superior frontal gyri (Fig. 2B). She again showed activation of the right middle temporal gyrus, while diffuse activation of midline structures, posterior association cortex, and the left inferior frontal gyrus was no longer evident. To confirm this interpretation, we statistically compared AM's postsurgical sing-rest run to her pre-surgical run (Fig. 2C). This showed significantly greater presurgical activation along the midline, in the angular and supramarginal gyri, the left inferior frontal gyrus (operculum), and occipital and mesial temporal regions (Table 2). Combined, these findings provide evidence that AM's singing network has become more focal following surgery coincident with improvements in her pitch accuracy of singing, with reduced post-surgical activation most conspicuous outside the typical singing network (compare Fig. 2C with Fig. 2D; see also Wilson et al., 20II).

[Insert Table 2 about here]

\subsubsection{Reorganisation of AM's singing function relative to pitch-matched controls}

The typical distribution (and variability) of activation during covert vocal singing in nonexperts is shown in the group penetrance map of the pitch-matched controls (Fig. 2D). It includes bilateral middle frontal and medial superior frontal gyri, left inferior frontal gyrus, bilateral superior temporal gyri, and cerebellum. When we statistically compared AM's pre-surgical activation for sing-rest with the pitch-matched controls, this supported the finding of a more distributed pattern 
of greater activation in AM, with no significant decrease in activation relative to controls (Fig. 2E). Significantly greater activation in AM included regions outside the typical singing network in the left frontal pole and paracingulate, left precuneus, and the hippocampal, parahippocampal and fusiform gyri (Table 3), with controls showing moderate deactivation in these mesial temporal regions.

To further illustrate the different patterns of activation observed for the pitch-matched controls and AM before surgery, Supplementary Fig. I contains the individual scans of three females of similar age and pitch accuracy of singing to AM, drawn from the larger pitch-matched control group. This clearly shows that the three healthy cases are similar to each other, activating key nodes of the nonexpert singing network during covert singing, yet they differ markedly from AM, who also showed diffuse activation along the midline spreading laterally into association cortex. Notably, AM's pattern of diffusely increased activation before surgery appeared largely specific to covert vocal singing, with no significant differences between her pre-surgical activation for speech-rest and the left-dominant language activation profile of pitch-matched controls ( $p>$ .05 for all comparisons). This is consistent with her normal behavioural performance of the outof-scanner verbal fluency task.

\section{[Insert Table 3 about here]}

Statistical comparison of AM's post-surgical activation for sing-rest with the pitchmatched controls showed there were no longer any regions in which activation differed in AM (P $>.05$ for all comparisons). We previously found that bilateral activation in anterior language regions (middle and inferior frontal gyri) was significantly reduced in experts compared to nonexperts during covert vocal singing (compare Fig. 2D with Fig. 2F; see also Wilson et al., 20II). Considered relative to her pre-operative scan, AM's post-operative scan reveals a change towards a more expert-like pattern, showing decreased activity in the inferior frontal gyri (particularly on the left), combined with less diffuse midline activation (Fig. $2 A-C$, slices $+40,+14$ ). Taken together, these findings suggest that her improved singing performance after tailored RATL 
was accompanied by reorganisation of her singing network into a more expert-like, focal pattern that was less coupled to language.

To ensure that AM's decreased post-operative activation profile was not simply an effect of repeat scanning, we collected data from three new nonexpert female singers of similar age to AM who performed an overt singing paradigm on two occasions, separated by a period of 12 weeks in which they received no singing training (see Supplementary Fig. 2 for details). This showed activation of the nonexpert singing network at both time points that, like the pitchmatched controls, was similar in each case but differed markedly from AM pre-surgery due to an absence of diffuse midline activation (Supplementary Fig. 2). The data also appeared robust across time, with minimal changes evident in activation patterns from time I to time 2 , starkly contrasting with the significant decrease in midline activation evident in AM's post-surgical scan

(Fig. 2B). This suggests that the changes in AM are unlikely to solely reflect test-retest effects, and more likely reflect real change. Finally, AM's post-surgical language study revealed a normal lefthemisphere activation profile, with no significant differences between her pattern of activation for speech-rest and the pitch-matched controls ( $P>.05$ for all comparisons). This is consistent with her stable post-operative performance of the out-of-scanner verbal fluency task.

\section{Discussion}

In this study, we present a case that illustrates that musical function, in particular the network supporting covert vocal singing, can show reorganisation accompanied by improved behavioural performance following resection of a long-standing epileptogenic lesion in the right temporal lobe. Despite evidence of overlap between the cortical networks mediating singing and language, particularly in nonexpert singers (Wilson et al., 20II), our experienced musician showed reorganisation of covert singing that appeared to occur largely independent of covert language through greater decoupling of these networks. In particular, after surgery AM showed isolated changes in her out-of-scanner overt singing performance and the pattern of activation accompanying her in-scanner covert singing. Her improved performance was associated with a 
more focal pattern of activation, including reduced activation of midline structures and posterior association cortex, and less recruitment of language structures as previously reported in experts (Wilson et al., 20II). It was also accompanied by AM's subjective experience of improved singing technique as well as seizure freedom, constituting a successful surgical outcome.

The findings suggest that the normal organisation of AM's singing network was selectively disrupted by her TLE before surgery when considered relative to her language network. The selectivity of these pre-operative effects is striking and presumably hampered AM's singing performance (while leaving language intact), producing a less expert and disorganised pattern of broadly spread activation that was atypical for someone of her singing experience. In this context, the visual and emotional strategies adopted by AM before surgery likely represent her attempt to maximise her singing performance by drawing on alternative modalities, and may have increased pre-operative activation in basic visual processing and association regions, such as occipital cortex, cuneus and precuneus, and the hippocampus and fusiform gyrus (Cavanna and Trimble, 2006; Hoscheidt et al., 2010).

To aid localisation of seizures, clinical epilepsy teams, including our own group, are increasingly using EEG-fMRI to visualise seizure networks in vivo (Archer et al., 2010; Carney et al., 2010; Flanagan et al., 2009; Pillay et al., in press). This work has shown BOLD signal changes along the midline spreading laterally into association cortex for paroxysmal fast activity, in patients with both focal and generalised epilepsy syndromes. The diffuse cortical activation displayed by AM before surgery was consistent with this pattern, and thus suggestive of generalised cortical hyperexcitability seen in medically intractable epilepsy. In addition, antiepileptic drugs have been shown to produce focal increases in fMRI activation during certain language tasks (Constable et al., 2004) and although this has not been directly investigated in singing, it may have contributed to AM's increased pattern of activation before surgery.

In nonexperts, the singing network typically includes bilateral middle and medial superior frontal gyri (sensorimotor, premotor, and supplementary motor areas), the left inferior frontal gyrus, bilateral superior temporal gyri (planum temporale), cingulate, insula, and cerebellum 
(Brown et al., 2004, 2006; Callan et al., 2006; Dalla Bella et al., 20I I; Hickok et al., 2003; Jeffries et al., 2003; Kleber et al., 2007, 2010; Koelsch et al., 2009; Özdemir et al., 2006; Perry et al., 1999; Riecker et al., 2000; Saito et al., 2006; Wildgruber et al., 1996; Wilson et al., 20II; Zarate and Zatorre, 2008). Before surgery, AM's partial activation of the nonexpert singing network and in particular, minimal activation of the right superior temporal gyrus augured well for her postoperative outcome. Nonetheless, she was counselled conservatively given the known risks of RATL to fine pitch discrimination and pitch working memory (Dennis and Hopyan, 200I; LiégeoisChauvel et al., 1998; Samson 1999; Samson and Zatorre, 1988, 1991, 1992; Wilson et al., 1999; Wilson and Saling 2008; Zatorre, 1985), which were preserved in AM before surgery and play a core role in singing. She then underwent a more tailored anterior temporal lobectomy that preserved the right superior temporal gyrus.

Following surgery, efficacious treatment of AM's epileptogenic network, accompanied by ongoing singing practice, presumably allowed a more expert singing network to emerge. The emergence of this network appeared to require reorganisation rather than just 'unmasking' because it involved decreased bilateral frontal activation, particularly in the left inferior frontal gyrus relative to AM's pre-operative activation. Reduced bilateral activation of language regions has been previously demonstrated in expert singers using counts of overlapping voxels for covert vocal singing and language tasks and argued to reflect decreased coupling of the singing and language networks (Wilson et al., 20I I). In addition, AM appeared less dependent on her visualisation strategy after surgery, with a subjective sense of greater singing proficiency accompanying her more focal activation pattern.

The case of AM provides an important contrast with the 31 year old amateur male musician described by McChesney-Atkins et al. (2003). This man experienced post-operative amusia (including poor singing) following right frontal resection of a long-standing lesion in the parasagittal region that was giving rise to 'singing seizures'. His post-operative language production and speech prosody remained intact, however, he was dissatisfied with his surgical outcome as he was unable to resume his role as a choral director. Juxtaposed, the two cases highlight the 
importance of taking the patient's pre-operative musical experience into account. Arguably, AM's extensive singing experience accompanied by an atypically organised singing network protected her against a poor musical outcome, with a more expert-like singing network emerging in the context of ongoing singing practice and seizure freedom after surgery. We consider it unlikely that this reorganisation was solely attributable to the effects of singing practice after surgery. Rather, AM's poor singing before surgery appeared to reflect the disruptive effects of seizures in her singing network. Previous research has investigated mechanisms underpinning poor pitch singing in otherwise healthy individuals who are 'tone deaf', and identified the role of pitch perception, memory, sensorimotor mapping, and motor control in accurate pitch production (Dalla Bella et al., 2007; Della Bella et al., 20I I; Hutchins and Peretz, 2012; Pfordresher and Brown, 2007). Since AM showed relatively preserved pitch discrimination and pitch working memory, cortical malformation of her right temporal lobe may have led to reorganisation of her singing network with 'downstream' disruption to sensorimotor mapping and motor control. However, more careful testing of her fine pitch discrimination would be required to evaluate this. Suarez et al. (2010) recently investigated eight patients with medically refractory epilepsy undergoing subdural electrode recordings for seizure localisation while singing familiar songs, reading prose, reciting familiar song lyrics, and humming. Despite differences between patients, they proposed a role for the right posterior superior temporal gyrus in singing that dissociated from the role of the left posterior superior temporal gyrus in speech for three patients. In the case of AM, the right middle temporal gyrus showed significant activation during covert vocal singing before and after surgery. This region has been previously linked to the song lexicon, and shown to activate when recognising familiar tunes (Platel et al., 2003) or perceiving new instrumental music (Brown et al., 2004). Its involvement may have supported AM's preserved pitch and melodic processing, and is consistent with research showing that reorganisation of function around the site of a lesion produces the most optimal functional outcomes, as compared to inter-hemispheric shifts in function (Matthews et al., 2004). 
There were some limitations of this study, including the possibility that repeat scanning accounted for the differences between AM's pre- and post-operative sing-rest scans. To address this issue we collected additional data from three nonexpert female singers of similar age to AM who performed an overt singing paradigm in-scanner on two separate occasions. Utilising data from an overt paradigm may provide a more conservative test of artefact due to participant motion in-scanner (i.e. repeatability may be expected to be worse for an overt task due to additional motion effects). Nevertheless the results showed that changes in the activation patterns over time were sparse and qualitatively different from those observed in AM. It is also the case that both males and females were included in the pitch-matched control group used in this study, despite more bilateral patterns of language activation typically reported in females (Wallentin, 2009). To address this issue we inspected the individual scans of three female pitch-matched controls who were similar in age to AM. This revealed that AM's pre-surgical pattern of activation was unique (also supported by the overt activation data), and highlighted the robustness of our covert singing task for activating the nonexpert singing network.

In conclusion, this case illustrates that seizures can selectively disrupt the functioning of the singing network, which may reorganise after efficacious surgery in a trained singer. There are a number of potential mechanisms that may account for this, including decoupling of the singing and language networks, augmented by ongoing singing training after surgery. Our case highlights the need to consider premorbid expertise in the counselling of epilepsy surgery candidates, and where appropriate, to tailor the resection to maximise the chances of an optimal surgical outcome. 


\section{Acknowledgements}

The authors sincerely thank AM for her willingness to be involved in this study over many years.

We would also like to thank T. O'Brien and other senior staff at the Royal Melbourne Hospital for their clinical input, and D. Lusher, R. S. Briellmann, A. B. Waites, M. Harvey, R. Bos and L. Hassaram for their assistance with data collection and analysis. Finally, we would like to acknowledge M.M. Saling for development of the orthographically-cued lexical retrieval task in our group.

\section{Funding}

This work was supported by funding from the Australian Research Council Discovery Projects scheme (DP0449862), the National Health and Medical Research Council Program Grant scheme (\#628952) and a Practitioner Fellowship to GDJ (\#527800), and the Victorian Government's Operational Infrastructure Support Program. 


\section{References}

Abbott $D$ and Jackson G. iBrain software for analysis and visualisation of functional MR images. Neurolmage, I3:S59, 2001.

Abbott DF, Masterton RAJ, Waites AB, Bhaganagarapu K, Pell GS, Harvey MR, Sharma GJ, and Jackson GD. The iBrain ${ }^{\mathrm{TM}}$ analysis toolbox for SPM. Proceedings of the 17th Annual Meeting of the Organisation for Human Brain Mapping, 20I I: 364.

Abbott DF, Waites AB, Lillywhite LM, and Jackson GD. fMRI assessment of language lateralization: An objective approach. Neurolmage, 50 (4): I446- I455, 2010.

Adcock JE, Wise RG, Oxbury JM, Oxbury SM, and Matthews PM. Quantitative fMRI assessment of the differences in lateralization of language-related brain activation in patients with temporal lobe epilepsy. Neurolmage, 18 (2):423-428, 2003.

Archer JS, Abbott DF, Masterton RAJ, Palmer SM, and Jackson GD. Functional MRI interactions between dysplastic nodules and overlying cortex in periventricular nodular heterotopia. Epilepsy \& Behavior, 19 (4):631-634, 2010.

Baxendale S. The impact of epilepsy surgery on cognition and behavior. Epilepsy \& Behavior, 12 (4):592-599, 2008.

Berl MM, Vaidya CJ, and Gaillard WD. Functional imaging of developmental and adaptive changes in neurocognition. Neurolmage, 30 (3):679-69I, 2006.

Brown S, Martinez MJ, Hodges DA, Fox PT, and Parsons LM. The song system of the human brain. Cognitive Brain Research, 20 (3):363-375, 2004.

Brown S, Martinez MJ, and Parsons, LM. Music and language side by side in the brain: A PET study of the generation of melodies and sentences. European Journal of Neuroscience, 23 (10):279I$2803,2006$.

Callan DE, Tsytsarev V, Hanakawa T, Callan AM, Katsuhara M, Fukuyama H, and Turner R. Song and speech: Brain regions involved with perception and covert production. Neurolmage, 3 I (3): I327-1342, 2006. 
Carney PW, Masterton RAJ, Harvey AS, Scheffer IE, Berkovic SF, and Jackson GD. The core network in absence epilepsy. Neurology, 75 (10):904-91 I, 2010.

Cavanna AE and Trimble MR. The precuneus: a review of its functional anatomy and behavioural correlates. Brain, 129 (3):564-583, 2006.

Chin PS, Berg AT, Spencer SS, Lee ML, Shinnar S, Sperling MR, Langfitt JT, Walczak TS, Pacia SV, Bazsil CW, Vassar S, and Vickrey BG. Patient-perceived impact of resective epilepsy surgery. Neurology, 66:1882-1887, 2006.

Chumbley JR and Friston KJ. False discovery rate revisited: FDR and topological inference using Gaussian random fields. Neurolmage, 44 (I):62-70, 2009.

Constable T, Hanick N, Arora J, Rajeevan N, Westerveld M, Spencer S, and Spencer D. Antiepileptogenic drug effects in fMRI language mapping. Epilepsia, 45:SI09, 2004.

Dalla Bella S, Giguere JF, and Peretz I. Singing proficiency in the general population. Journal of the Acoustical Society of America, I2I (2): I I82-I I89, 2007.

Dalla Bella S, Berkowska M, and Sowinski J. Disorders of pitch production in tone deafness. Frontiers in Psychology, 2:164, 2011.

Degé $\mathrm{F}$ and Schwarzer $\mathrm{G}$. The effect of a music program on phonological awareness in preschoolers. Frontiers in Psychology, 2:124, 2011.

Dennis $M$ and Hopyan T. Rhythm and melody in children and adolescents after left or right temporal lobectomy. Brain and Cognition, 47 (3):46I-469, 200 I.

Desikan RS, Ségonne F, Fischl B, Quinn BT, Dickerson BC, Blacker D, Buckner RL, Dale AM, Maguire RP, Hyman BT, Albert MS, and Killiany RJ. An automated labeling system for subdividing the human cerebral cortex on MRI scans into gyral based regions of interest. Neurolmage, 31 (3):968-980, 2006.

Federico P. Language reorganization in early onset temporal lobe epilepsy. Epilepsia, 52 (Suppl. 4):47-48, 2011.

Flanagan D, Abbott DF, and Jackson GD. How wrong can we be? The effect of inaccurate markup of EEG/fMRI studies in epilepsy. Clinical Neurophysiology, 120 (9):1637-1647, 2009. 
Formby C, Thomas RG, and Halsey JH. Regional cerebral blood flow for singers and nonsingers while speaking, singing, and humming a rote passage. Brain and Language, 36: 690-698, 1989.

Fox PT, Ingham RJ, Ingham JC, Hirsch TB, Downs JH, Martin C, Jerabek P, Glass T, and Lancaster JL. A PET study of the neural systems of stuttering. Nature, 382:158-162, 1996.

Friston KJ, Glaser DE, Henson RN, Kiebel S, Phillips C, and Ashburner J. Classical and Bayesian inference in neuroimaging: applications. Neurolmage, 16:484-512, 2002.

Gaillard WD, Berl MM, Moore EN, Ritzl EK, Rosenberger LR, Weinstein SL, Conry JA, Pearl PL, Ritter FF, Sato S, Vezina LG, Vaidya CJ, Wiggs E, Fratalli C, Risse G, Ratner NB, Gioia G, and Theodore WH. Atypical language in lesional and nonlesional complex partial epilepsy. Neurology, 69 (18):176I-I77I, 2007.

Hickok G, Buchsbaum B, Humphries C, and Muftuler T. Auditory-motor interaction revealed by fMRI: Speech, music, and working memory in area SPT. Journal of Cognitive Neuroscience, 15 (5):673-682, 2003.

Hoscheidt SM, Nadela L, Payneb J, and Ryan L. Hippocampal activation during retrieval of spatial context from episodic and semantic memory. Behavioural Brain Research, 212:121-132, 2010.

Hsieh S, Hornberger M, Piguet $\mathrm{O}$, and Hodges J. Neural basis of music knowledge: evidence from the dementias. Brain, 134 (9):2523-34.

Hyde KL, Peretz I, and Zatorre RJ. Evidence for the role of the right auditory cortex in fine pitch resolution. Neuropsychologia, 46 (2):632-639, 2008.

Hutchins SM and Peretz I. A frog in your throat or in your ear? Searching for the causes of poor singing. Journal of Experimental Psychology: General, I4I (I):76-97, 2012.

Jeffries KJ, Fritz JB, and Braun, AR. Words in melody: An H2I5O PET study of brain activation during singing and speaking. Neuroreport I4 (5):749-754, 2003.

Kleber B, Birbaumer N, Veit R, Trevorrow T, and Lotze M. Overt and imagined singing of an Italian aria. Neurolmage, 36 (3):889-900, 2007.

Kleber B, Veit R, Birbaumer N, Gruzelier J, and Lotze M. The brain of opera singers: Experiencedependent changes in functional activation. Cerebral Cortex, 20 (5): I I44-I I52, 20 I0. 
Koelsch S, Schulze K, Sammler D, Fritz T, Müller K, and Gruber O. Functional architecture of verbal and tonal working memory: An FMRI study. Human Brain Mapping, 30 (3):859-873, 2009.

Langfitt JT, Westerveld M, Hamberger MJ, Walczak TS, Cicchetti DV, Berg AT, Vickrey BG, Barr WB, Sperling MR, Masur D, and Spencer SS. Worsening of quality of life after epilepsy surgery. Neurology, 68 (23):1988-1994, 2007.

Liégeois-Chauvel C, Peretz I, Babaï M, Laguitton V, and Chauvel P. Contribution of different cortical areas in the temporal lobes to music processing. Brain, 2I (10):1853-1867, 1998.

Marie C, Delogu F, Lampis G, Belardinelli MO, and Besson M. Influence of musical expertise on segmental and tonal processing in Mandarin Chinese. Journal of Cognitive Neuroscience, 23 (I0):270I-I5, 2011.

Matthews PM, Johansen-Berg $\mathrm{H}$, and Reddy $\mathrm{H}$. Non-invasive mapping of brain functions and brain recovery: Applying lessons from cognitive neuroscience to neurorehabilitation. Restorative Neurology and Neuroscience, 22 (3-5):245-260, 2004.

Mbwana J, Berl MM, Ritzl EK, Rosenberger L, Mayo J, Weinstein S, Conry JA, Pearl PL, Shamim S, Moore EN, Sato S, Vezina LG, Theodore WH, and Gaillard WD. Limitations to plasticity of language network reorganization in localization related epilepsy. Brain, 132 (2):347-356, 2009.

McChesney-Atkins S, Davies KG, Montouris GD, Silver JT, and Menkes DL. Amusia after right frontal resection for epilepsy with singing seizures: Case report and review of the literature. Epilepsy \& Behavior, 4 (3):343-347, 2003.

Merrett D and Wilson SJ. Music and neural plasticity. In: Rickard NS, and McFerran K (Eds). Lifelong Engagement with Music: Benefits for Mental Health and Well-being. New York: Nova Science Publishers, 2012: 123-162.

Moreno S, Marques C, Santos A, Santos M, Castro SL, and Besson M. Musical training influences linguistic abilities in 8-year-old children: more evidence for brain plasticity. Cerebral Cortex, 19 (3):7I 2-23, 2009. 
Münte TF, Altenmüller E, and Jäncke L. The musician's brain as a model of neuroplasticity. Nature Reviews Neuroscience, 3: 473-478, 2002.

Ogawa S, Lee TM, Kay AR, and Tank DW. Brain magnetic resonance imaging with contrast dependent on blood oxygenation. Proceedings of the National Academy of Sciences USA, 87 (24):9868-9872, 1990.

Özdemir E, Norton A, and Schlaug G. Shared and distinct neural correlates of singing and speaking. Neurolmage, 33 (2):628-635, 2006.

Perry DW, Zatorre RJ, Petrides, M, Alivisatos B, Meyer E, and Evans AC. Localization of cerebral activity during simple singing. Neuroreport, 10 (18):3979-3984, 1999.

Pfordresher PQ and Brown S. Poor-pitch singing in the absence of "tone deafness". Music Perception, 25 (2):95- II5, 2007.

Platel H, Baron JC, Desgranges B, Bernard F, and Eustache F. Semantic and episodic memory of music are subserved by distinct neural networks. Neurolmage, 20 (I):244-256, 2003.

Pillay N, Badawy RAB, Flanagan DF, Archer JS, Berkovic SF, and Jackson GD. EEG-fMRI in LennoxGastaut syndrome: Fast and slow spike wave networks. Annals of Neurology, in press.

Riecker A, Ackermann H, Wildgruber D, Dogil G, and Grodd W. Opposite hemispheric lateralization effects during speaking and singing at motor cortex, insula and cerebellum. Neuroreport, II (9):1997-2000, 2000.

Rose KJ, Derry PA, and McLachlan RS. Patient expectations and postoperative depression, anxiety, and psychosocial adjustment after temporal lobectomy: A prospective study. International Journal of Behavioral Medicine, 2 (I):27-40, 1995.

Saito Y, Ishii K, Yagi K, Tatsumi IF, and Mizusawa H. Cerebral networks for spontaneous and synchronized singing and speaking. Neuroreport, 17 (18):|893-1897, 2006.

Saling MM. Verbal memory in mesial temporal lobe epilepsy: Beyond material specificity. Brain, I32 (3):570-582, 2009.

Sammler D, Koelsch S, and Friederici AD. Are left fronto-temporal brain areas a prerequisite for normal music-syntactic processing? Cortex, 47 (6):659-73, $201 \mathrm{I}$. 
Samson S. Musical function and temporal lobe structures: A review of brain lesion studies. Journal of New Music Research, 28 (3):217-228, 1999.

Samson S and Zatorre RJ. Melodic and harmonic discrimination following unilateral cerebral excision. Brain and Cognition, 7 (3):348-360, 1988.

Samson S and Zatorre RJ. Recognition memory for text and melody of songs after unilateral temporal lobe lesion: evidence for dual encoding. Journal of Experimental Psychology: Learning, Memory, and Cognition, 17 (4):793-804, 1991.

Samson S and Zatorre RJ. Learning and retention of melodic and verbal information after unilateral temporal lobectomy. Neuropsychologia, 30 (9):8I5-826, 1992.

Schön D, Gordon RL, and Besson M. Musical and linguistic processing in song perception. Annals of the New York Academy of Sciences, 1060:7I-8I, 2005.

Scott RC, Gadian DG, Cross JH, Wood SJ, Neville BGR, and Connelly A. Quantitative magnetic resonance characterization of mesial temporal sclerosis in childhood. Neurology, 56 (I2):1659-1665, 2001.

Strauss E, Sherman EMS, and Spreen O. A Compendium of Neuropsychological Tests: Administration, Norms and Commentary (3rd ed.). New York: Oxford University Press, 2006.

Suarez RO, Golby A, Whalen S, Sato S, Theodore WH, Kufta CV, Devinsky O, Balish M, and Bromfield EB. Contributions to singing ability by the posterior portion of the superior temporal gyrus of the non-language-dominant hemisphere: First evidence from subdural cortical stimulation, Wada testing, and fMRI. Cortex, 46:343-353, 2010.

Sveller C, Briellmann RS, Saling MM, Lillywhite L, Abbott DF, Masterton RAJ, and Jackson GD. Relationship between language lateralization and handedness in left-hemispheric partial epilepsy. Neurology, 67 (10):1813-1817, 2006.

Taylor DC, McMackin D, Staunton H, Delanty N, and Phillips J. Patients' aims for epilepsy surgery: desires beyond seizure freedom. Epilepsia, 42 (5):629-633, 2001. 
Waites AB, Briellmann RS, Saling MM, Abbott DF, and Jackson GD. Functional connectivity networks are disrupted in left temporal lobe epilepsy. Annals of Neurology, 59 (2):335-343, 2006.

Wallentin M. Putative sex differences in verbal abilities and language cortex: A critical review. Brain \& Language, 108:175-183, 2009.

Wheelock, I. Expectations and life changes associated with surgery for intractable epilepsy. Journal of Epilepsy, II:48-57, 1998.

Wildgruber D, Ackermann H, Klose U, Kardatzki B, and Grodd W. Functional lateralization of speech production at primary motor cortex: A fMRI study. Neuroreport, 7 (I5- I7):279|-2795, 1996.

Wilke C, Worrell G, He B. Graph analysis of epileptogenic networks in human partial epilepsy. Epilepsia, 52 (I):84-93, $201 \mathrm{I}$.

Wilson SJ, Abbott DF, Lusher D, Gentle EC, and Jackson GD. Finding your voice: A singing lesson from functional imaging. Human Brain Mapping, 32 (I2):2II5-2I30, 201 I.

Wilson SJ, Bladin PF, and Saling MM. The burden of normality: A framework for rehabilitation after epilepsy surgery. Epilepsia, 48 (Suppl. 9):13-16, 2007.

Wilson SJ, Lusher D, Martin CL, Rayner G, and McLachlan, NM. Intersecting factors lead to absolute pitch acquisition that is maintained in a "fixed do" environment. Music Perception, 29:285-296, 2011 .

Wilson SJ, Pressing J, Wales RJ, and Pattison P. Cognitive models of music psychology and the lateralisation of musical function within the brain. Australian Journal of Psychology, 5 I (3):I25139, 1999.

Wilson SJ and Saling MM. Contributions of the left and right mesial temporal lobes to music memory: Evidence from melodic learning difficulties. Music Perception, 25 (4):303-3।4, 2008.

Wilson SJ, Saling MM, Kincade P, and Bladin PF. Patient expectations of temporal lobe surgery. Epilepsia, 39 (2): 167-174, 1998. 
Wood AG, Saling MM, Abbott DF, and Jackson GD. A neurocognitive account of frontal lobe involvement in orthographic lexical retrieval: Preliminary insights with fMRI. Neurolmage, 14:162-169, 2001.

Zarate JM and Zatorre RJ. Experience-dependent neural substrates involved in vocal pitch regulation during singing. Neurolmage, 40 (4): |87|-|887, 2008.

Zatorre RJ. Discrimination and recognition of tonal melodies after unilateral cerebral excisions. Neuropsychologia, 23 (I):3I-4I, 1985.

Zatorre RJ. Intact absolute pitch ability after left temporal lobectomy. Cortex, 25 (4):567-580, 1989.

Zatorre RJ, Belin P, Penhune VB. Structure and function of auditory cortex: music and speech. Trends in Cognitive Sciences, 6 (I):37-46, 2002.

Zatorre RJ and Samson S. Role of the right temporal neocortex in retention of pitch in auditory short-term memory. Brain, II4 (6):2403-24I7, 1991.

Zatorre RJ, Evans AC, and Meyer E. Neural mechanisms underlying melodic perception and memory for pitch. The Journal of Neuroscience, 14 (4):1908-1919, 1994. 


\section{Figure legends}

Fig. I - 3T structural MRIs of AM before and I5-months after surgery. (A) Pre-operative TIweighted sequence showing cortical dysplasia centred on the superior temporal gyrus in both temporal lobes, extending into the right parahippocampal gyrus. The right temporal lobe and hippocampus are also smaller without evidence of hippocampal sclerosis (coronal slices, note that the left hemisphere is on the right). (B) Post-operative T2-weighted sequence showing the extent of the right temporal lobectomy, including en-bloc resection of lateral and mesial temporal structures. Focal cortical dysplasia of the right temporal neocortex (arrow) was confirmed on histopathology of the resected specimen (axial slice, left hemisphere on the right).

Fig. 2 - fMRI activation for covert vocal singing (sing-rest) in AM and the pitch-matched controls.

(A) Before surgery, AM showed an atypical pattern characterised by partial activation of the nonexpert singing network (see panel $D$ ) as well as diffuse activation of midline structures and posterior association cortex. (B) After surgery, AM showed a more expert-like focal pattern (see panel F) characterised by activation of the singing network, and reduced activation of midline structures, posterior association cortex, and the left inferior frontal gyrus. (C) Statistical parametric map of significant differences between AM's pre- and post-surgical scans (panel A versus $B)$. There are no regions in which AM exhibited significantly more activity after surgery, confirming her more focal pattern of activation (see Table 2 for peak co-ordinates). (D) Group penetrance map $(n \geq 2)$ derived from the individual topological-false-discovery-rate corrected tmaps of the 12 pitch-matched controls, showing activation typical of nonexpert singers. (E) Statistical parametric map indicating where AM's pre-surgical activation is significantly greater than the pitch-matched controls (panel A versus D). Consistent with panel (A), this shows a more distributed pattern of increased activation in AM, with no regions where AM has significantly less activity than controls (see Table 3 for peak co-ordinates). (F) Group penetrance map ( $n \geq 2)$ derived from the individual topological-false-discovery-rate corrected t-maps of 10 expert singers, 
showing decreased bilateral frontal activation particularly on the right in expert singers (data taken from Wilson et al., 20II).

Note. The left hemisphere is on the right for all axial slices shown; $\mathrm{mSFG}=$ medial superior frontal gyrus; MFG = middle frontal gyrus; IFG = inferior frontal gyrus; STG = superior temporal gyrus; MTG = middle temporal gyrus . 
Table I - Characteristics of AM and the pitched-matched controls as compared to expert singers

\begin{tabular}{|c|c|c|c|c|}
\hline \multirow[t]{2}{*}{ Characteristic } & \multicolumn{2}{|c|}{ Patient AM } & \multirow{2}{*}{$\begin{array}{l}\text { Healthy Controls } \\
\qquad(n=12)\end{array}$} & \multirow{2}{*}{$\begin{array}{l}\text { Expert singers } \\
\qquad(\mathrm{n}=10)\end{array}$} \\
\hline & Pre-op & Post-op & & \\
\hline Number of females & 1 & I & 6 & 8 \\
\hline $\begin{array}{l}\text { Mean age }(y r s \pm S D) \\
\text { range }\end{array}$ & 26 & 27 & $\begin{array}{l}34.3(14.8) \\
18-52\end{array}$ & $\begin{array}{l}30.6(9.9) \\
19-50\end{array}$ \\
\hline $\begin{array}{l}\text { Mean education (yrs } \pm \text { SD) } \\
\text { range }\end{array}$ & 19 & 20 & $\begin{array}{l}15.5(2.6) \\
11-20\end{array}$ & $\begin{array}{l}17.2(3.5) \\
12-25\end{array}$ \\
\hline $\begin{array}{l}\text { Mean pitch accuracy }(\% \pm S D) \\
\text { range }^{b}\end{array}$ & 50 & 60 & $\begin{array}{l}52.4(10.2) \\
36.7-65.2\end{array}$ & $\begin{array}{l}81.2(8.9) \\
70.5-98.1\end{array}$ \\
\hline $\begin{array}{l}\text { Mean singing experience (yrs } \pm S D) \\
\text { range }^{c}\end{array}$ & 14 & 15 & $\begin{array}{c}0.9(2.2) \\
0-6\end{array}$ & $\begin{array}{c}10.4(9.6) \\
0-30\end{array}$ \\
\hline $\begin{array}{l}\text { Mean pitch discrimination (SD) } \\
\left.\text { range }^{d, e} \text { (total score of } 44\right)\end{array}$ & 44 & 44 & $\begin{array}{c}43.7(0.7) \\
42-44\end{array}$ & $\begin{array}{c}43.9(0.4) \\
43-44\end{array}$ \\
\hline 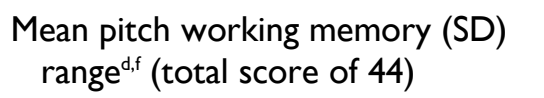 & 43 & 43 & $\begin{array}{c}42.3(1.8) \\
39-44\end{array}$ & $\begin{array}{c}43.9(0.4) \\
43-44\end{array}$ \\
\hline $\begin{array}{l}\text { Mean COWAT score (SD) } \\
\text { range }^{\mathrm{d}, \mathrm{g}}\end{array}$ & 37 & 39 & $\begin{array}{l}44.8(13.6) \\
13-57\end{array}$ & $\begin{array}{c}46.3(7.4) \\
35-55\end{array}$ \\
\hline
\end{tabular}

Note. All participants were native English speakers.

${ }^{\text {aD }}$ ata for the expert singers is taken from Wilson et al. (20II).

${ }^{\mathrm{b}}$ The method for assessing pitch accuracy is described in the experimental procedures and is derived from Wilson et al. (2011)

'Singing experience was based on the total number of years participants reported they had been actively engaged in singing practice, such as public performances, choral singing, and formal singing training. These activities typically occurred simultaneously and were less evident in the healthy controls compared to AM, who had a singing experience profile typical of an expert. Note there was I case of missing data for the expert singers group.

${ }^{\mathrm{d}}$ There were two cases of missing data from the pitch-matched control group and the expert singers group. Note for the COWAT there was only I case of missing data for the expert singers group.

${ }^{\mathrm{e}}$ Assessed using the control condition of the pitch working memory task developed by Zatorre and colleagues (1991, 1994).

fAssessed using the interference condition of the pitch working memory task developed by Zatorre and colleagues (1991, 1994).

${ }^{8}$ Normative data for the Controlled Oral Word Association Test (COWAT) indicates a mean of $39.3 \pm$ II .6 (Spreen and Strauss, 2006). 
Table 2 - Peak co-ordinates of AM's pre- minus post-surgical activation for sing-rest.

\begin{tabular}{lcccccc}
\hline Activated clusters & \multicolumn{2}{c}{ MNI co-ordinates } & $\begin{array}{c}t \text {-value } \\
\text { (SPM) }\end{array}$ & $\begin{array}{c}\text { FDRc } P \text {-value } \\
\text { (SPM) }\end{array}$ \\
\hline Cortical regions & & & & & \\
Left angular/supramarginal gyrus (BA 40) & -62 & -54 & 32 & 4.3 & 0.018 \\
Right angular/supramarginal gyrus (BA 40) & 52 & -44 & 26 & 4.4 & 0.010 \\
Left frontal orbital cortex (BA 13) & -28 & 20 & -16 & 5.7 & 0.000 \\
Left occipital pole (BA 17) & -14 & -92 & 6 & 5.1 & 0.000 \\
Right occipital pole (BA 19) & 28 & -94 & 20 & 5.3 & 0.002 \\
Midline cortical and mesial temporal regions & & & & & \\
Paracingulate gyrus (BA 9) & 0 & 48 & 22 & 5.0 & 0.000 \\
Precuneus (BA 29) & 2 & -54 & 8 & 5.2 & 0.000 \\
Cuneal cortex (BA 19) & 2 & -90 & 34 & 4.3 & 0.001 \\
Left fusiform gyrus (BA 18) & -26 & -82 & -8 & 4.7 & 0.046 \\
Left hippocampus & -30 & -16 & -14 & 4.2 & 0.012 \\
\hline
\end{tabular}

Note. Brodmann Areas (BA) were determined by converting MNI coordinates to Talairarch coordinates using mni2tal (http://imaging.mrc-cbu.cam.ac.uk/downloads/MNI2tal/mni2tal.m), then using the Talairarch daemon (http://www.talairach.org/daemon.html). 
Table 3 - Peak co-ordinates of pre-surgical activation in AM compared to controls for sing-rest.

\begin{tabular}{lcccccc}
\hline Activated clusters & $\begin{array}{c}\text { MNI co- } \\
\text { ordinates }\end{array}$ & $\begin{array}{c}t \text {-value } \\
\text { (SPM) }\end{array}$ & $\begin{array}{c}\text { FDRc } P \text {-value } \\
\text { (SPM) }\end{array}$ \\
\hline Cortical regions & -4 & 62 & 26 & 7.69 & 0.026 \\
Left frontal pole \& paracingulate (BA9) & -14 & 14 & 52 & 8.19 & 0.033 \\
Left superior frontal gyrus (BA6) & -10 & -64 & 68 & 7.09 & 0.000 \\
Left precuneus (BA7) & & & & & \\
Mesial temporal regions & -30 & -30 & -20 & 8.58 & 0.002 \\
Left parahippocampal gyrus \& hippocampus (BA36) & -18 & -80 & -24 & 7.08 & 0.000 \\
Right fusiform \& parahippocampal gyrus (BA36) & 10 & & & \\
\hline
\end{tabular}

Note. Brodmann Areas (BA) were determined by converting MNI coordinates to Talairarch coordinates using mni2tal (http://imaging.mrc-cbu.cam.ac.uk/downloads/MNI2tal/mni2tal.m), then using the Talairarch daemon (http://www.talairach.org/daemon.html). 


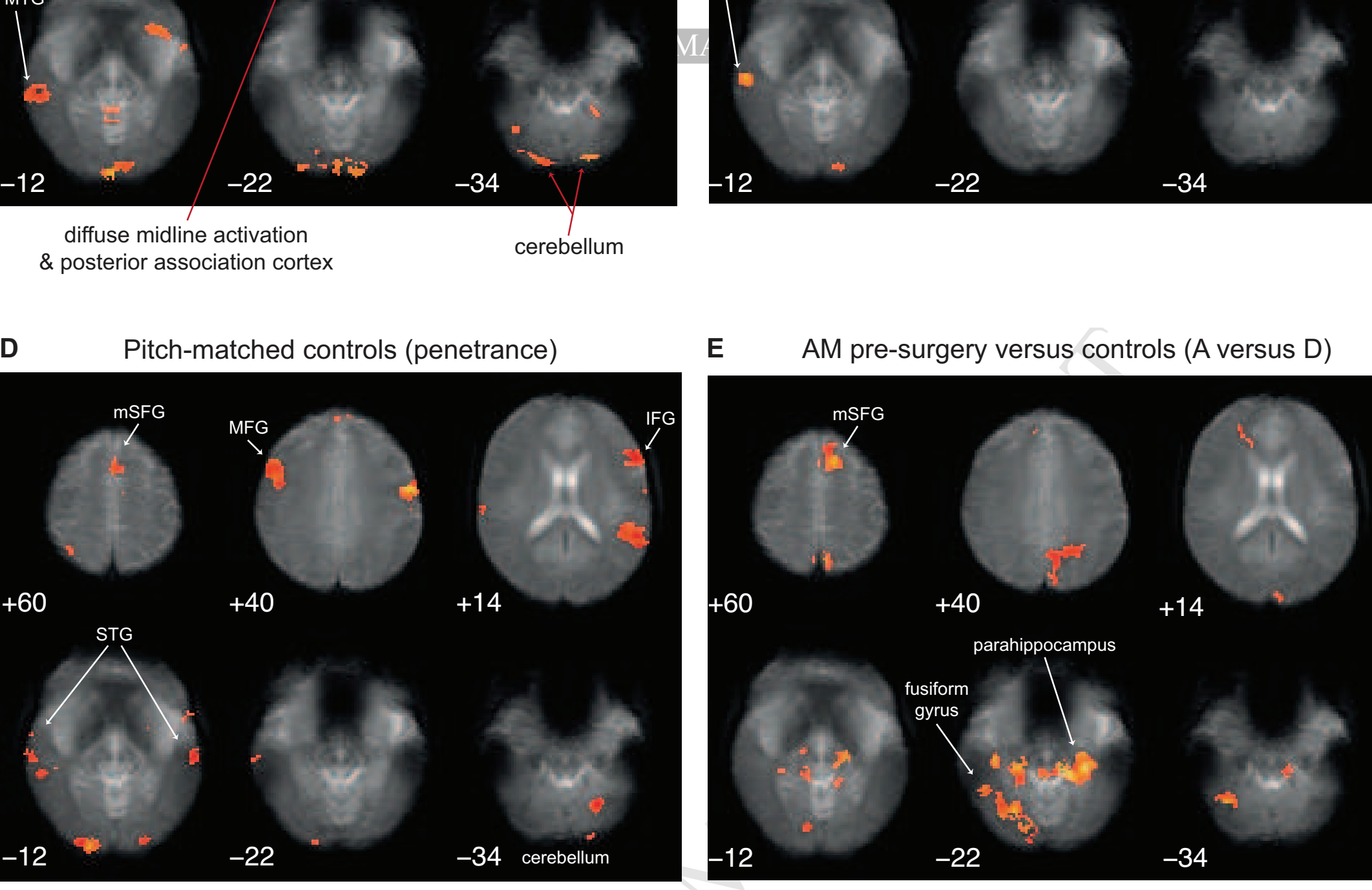


26 year old female Singing pitch accuracy score $=62$
24 year old female

Singing pitch accuracy score $=58$
21 year ol Singing pi
Case AM: Sing-rest before surgery (from Fig. 2A)

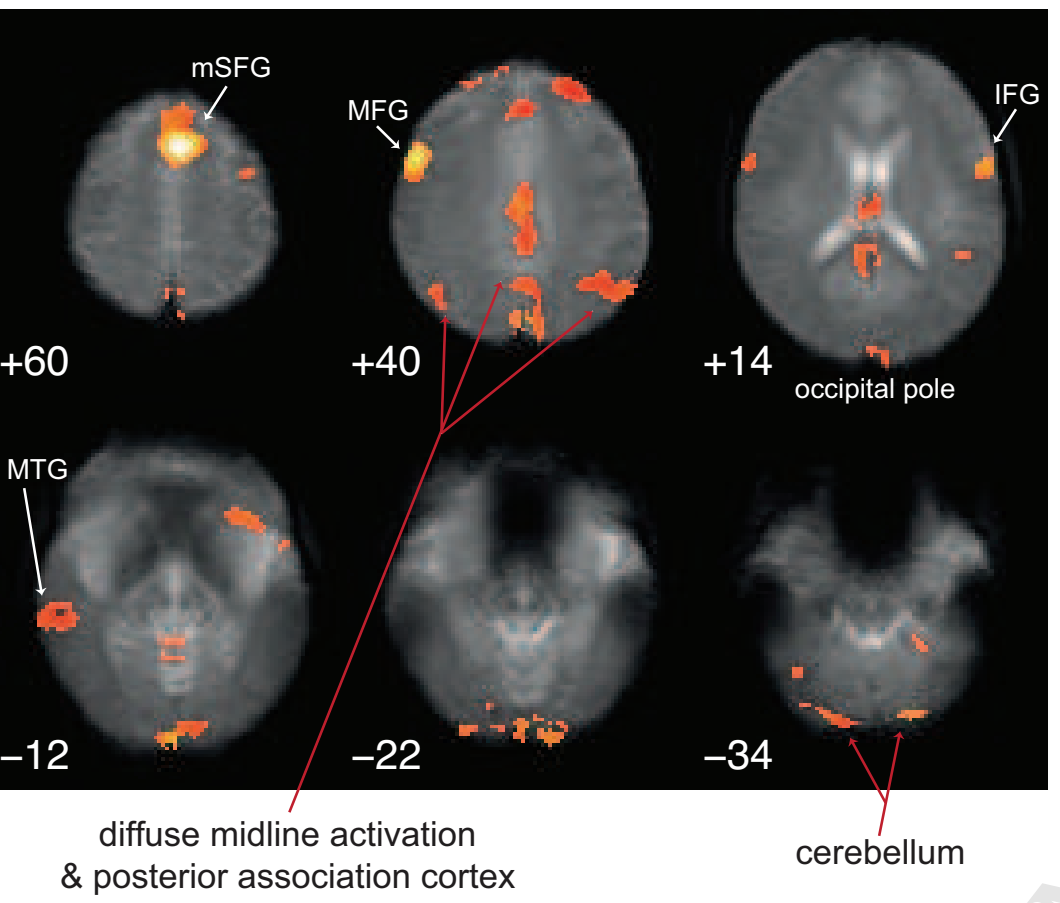

26 year old female

Singing pitch accuracy score $=50$
Pitch-matched controls (penetrance) (from Fig. 2D)

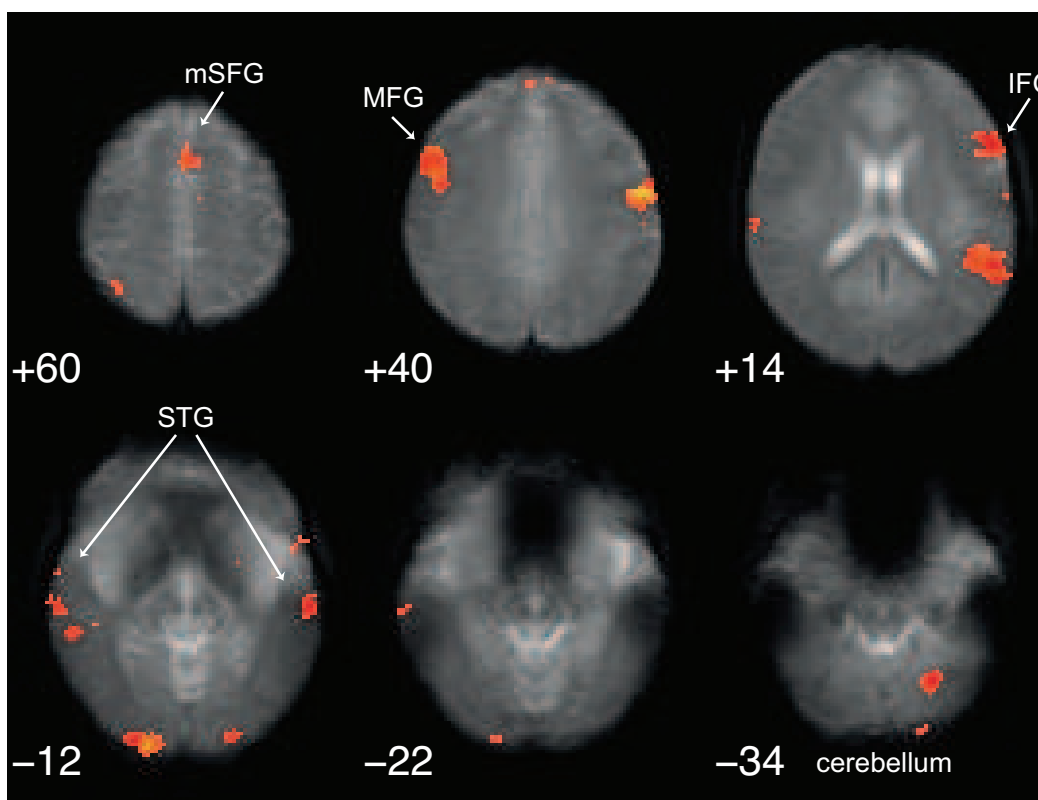

(axial slice
Mean age 34 years (SD $=15), 6$ females $\& 6$ males Mean singing pitch accuracy score $=52(S D=10)$ 
B Time 1 (sing-exhale)

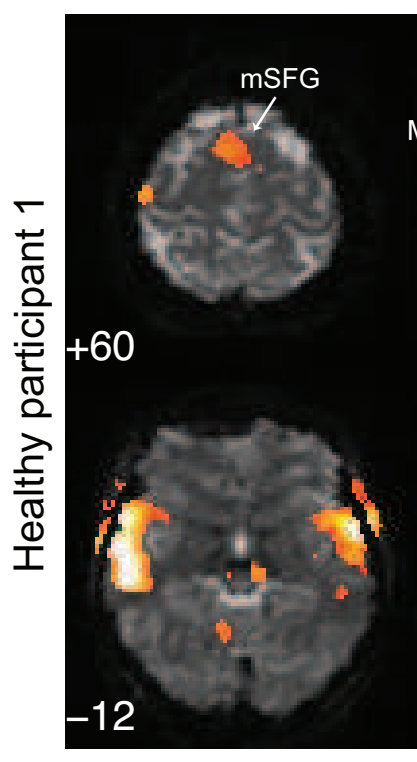

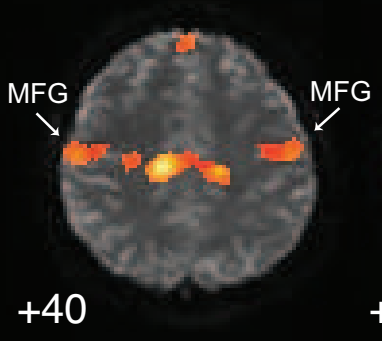
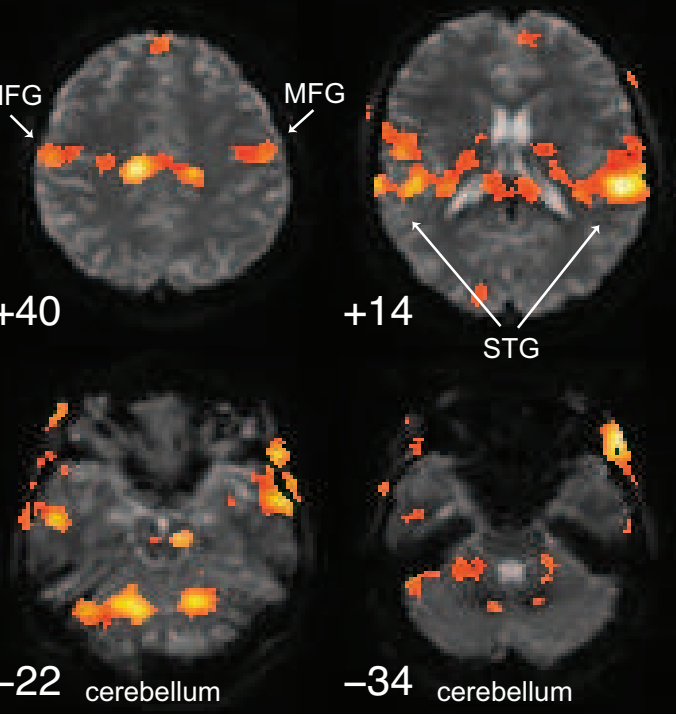

C Time 2 (sing-exhale)

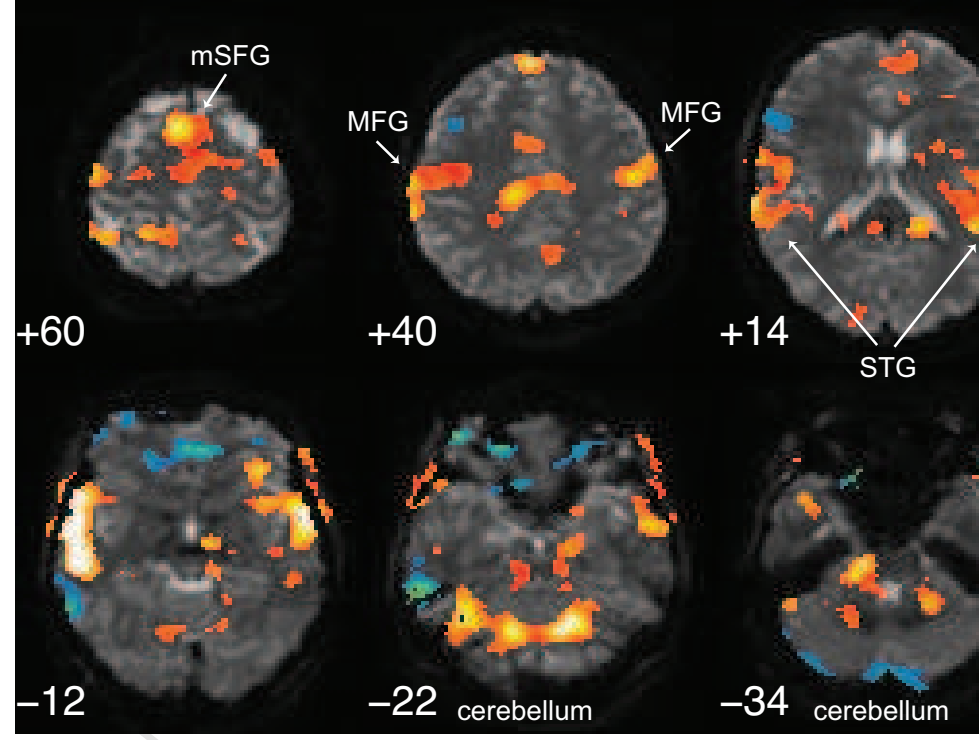

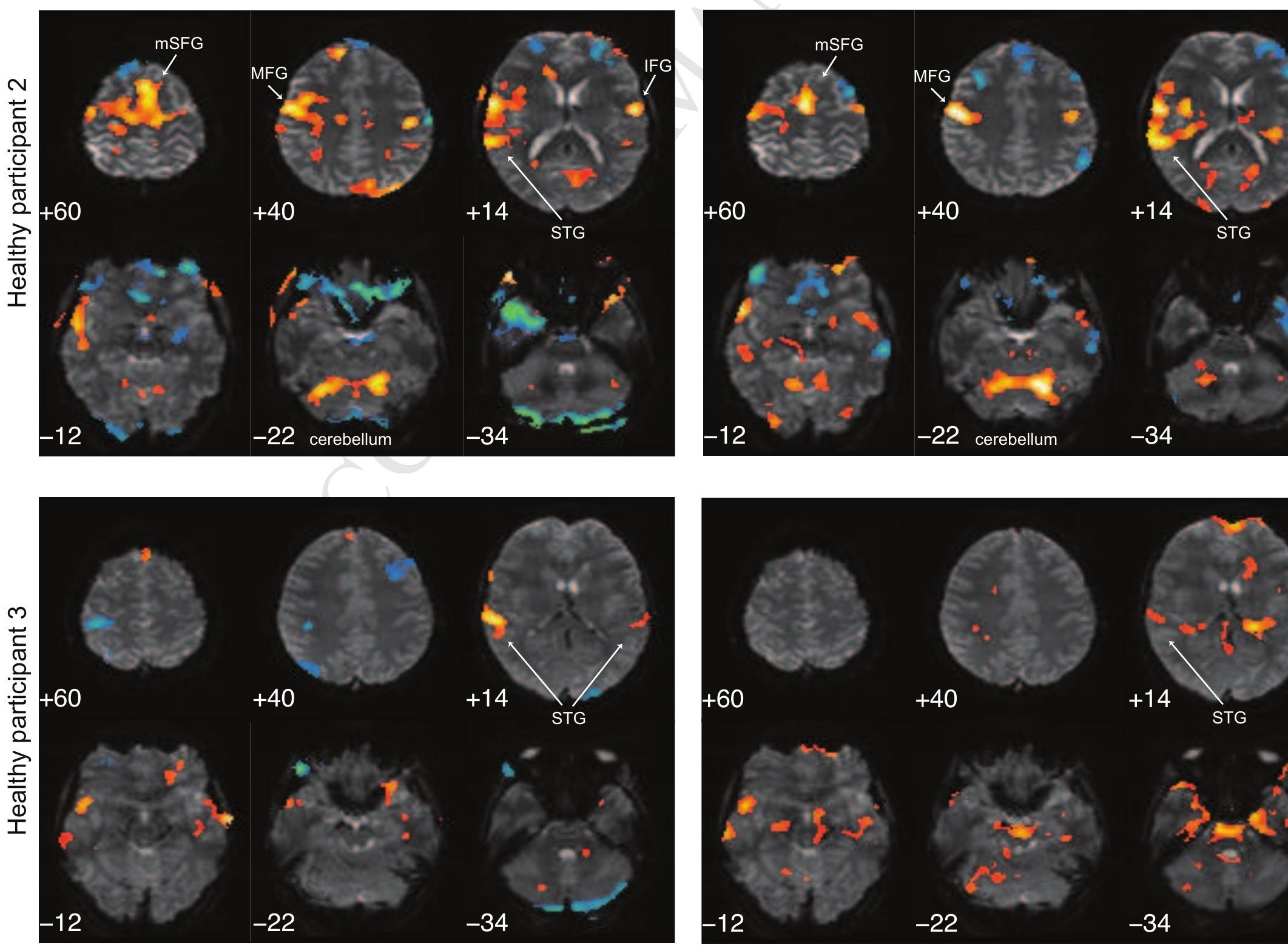




\section{University Library}

\section{- M M N E R VA A gateway to Melbourne's research publications}

Minerva Access is the Institutional Repository of The University of Melbourne

Author/s:

Wilson, SJ;Abbott, DF;Tailby, C;Gentle, EC;Merrett, DL;Jackson, GD

Title:

Changes in singing performance and fMRI activation following right temporal lobe surgery

Date:

2013-10-01

Citation:

Wilson, S. J., Abbott, D. F., Tailby, C., Gentle, E. C., Merrett, D. L. \& Jackson, G. D. (2013).

Changes in singing performance and $\mathrm{fMRI}$ activation following right temporal lobe surgery.

CORTEX, 49 (9), pp.2512-2524. https://doi.org/10.1016/j.cortex.2012.12.019.

Publication Status:

Accepted manuscript

Persistent Link:

http://hdl.handle.net/11343/41855 